\title{
Conserving large populations of lions - the argument for fences has holes
}

\author{
Authors: S. Creel, M. S. Becker, S. M. Durant, J. M'Soka, W. Matandiko, A. J. Dickman, \\ D. Christianson, E. Dröge, T. Mweetwa, N. Pettorelli, E. Rosenblatt, P. Schuette, R. \\ Woodroffe, S. Bashir, R. C. Beudels-Jamar, S. Blake, M. Borner, C. Breitenmoser, F. \\ Broekhuis, G. Cozzi, T. R. B. Davenport, J. Deutsch, L. Dollar, S. Dolrenry, I. Douglas- \\ Hamilton, E. Fitzherbert, C. Foley, L. Hazzah, P. Henschel, R. Hilborn, J. G. C. Hopcraft, \\ D. Ikanda, A. Jacobson, B. Joubert, D. Joubert, M. S. Kelly, L. Lichtenfeld, G. M. Mace, J. \\ Milanzi, N. Mitchell, M. Msuha, R. Muir, J. Nyahongo, S. Pimm, G. Purchase, C. Schenck, \\ C. Sillero-Zubiri, A. R. E. Sinclair, A. N. Songorwa, M. Stanley-Price, C. A. Tehou, C. \\ Trout, J. Wall, G. Wittemyer and A. Zimmermann
}

This is the peer reviewed version of the following article: Creel, S., Becker, M. S., Durant, S. M., M'Soka, J., Matandiko, W., Dickman, A. J., ... Pettorelli, N. (2013). Conserving large populations of lions - the argument for fences has holes. Ecology Letters 16(11), 1413-e3, which has been published in final form at http://dx.doi.org/10.1111/ele.12145 This article may be used for noncommercial purposes in accordance with Wiley Terms and Conditions for Self-Archiving.

Creel, S., Becker, M. S., Durant, S. M., M'Soka, J., Matandiko, W., Dickman, A. J., ... Pettorelli, N. (2013). Conserving large populations of lions - the argument for fences has holes. Ecol Lett, 16(11), 1413-e3. doi:10.1111/ele.12145

Made available through Montana State University's ScholarWorks scholarworks. montana.edu 


\section{Conserving large populations of lions - the argument for fences has holes}

S. Creel, ${ }^{1 *}$ M. S. Becker, ${ }^{1,2}$ S. M. Durant, ${ }^{3,4}$ J. M'Soka, ${ }^{1,5}$ W. Matandiko, ${ }^{1,2}$ A. J. Dickman, ${ }^{6}$ D. Christianson, ${ }^{7}$ E. Dröge, ${ }^{2}$ T. Mweetwa, ${ }^{2}$ N. Pettorelli, ${ }^{3}$ E. Rosenblatt, ${ }^{1,2}$ P. Schuette, ${ }^{1,2}$ R. Woodroffe, ${ }^{3}$ S. Bashir, ${ }^{3}$ R. C. BeudelsJamar, ${ }^{8,9}$ S. Blake, ${ }^{10}$ M. Borner, ${ }^{11}$ C. Breitenmoser, ${ }^{12}$ F. Broekhuis, ${ }^{6}$ G. Cozzi, ${ }^{13}$ T. R. B. Davenport, ${ }^{14}$ J. Deutsch, ${ }^{4}$ L. Dollar, ${ }^{15,16,17}$ S. Dolrenry, ${ }^{18}$ I. Douglas-Hamilton, ${ }^{19,20}$ E. Fitzherbert, ${ }^{6,21}$ C. Foley, ${ }^{14}$ L. Hazzah, ${ }^{18}$ P. Henschel, ${ }^{22}$ R. Hilborn, ${ }^{23}$ J. G. C. Hopcraft, ${ }^{11}$ D. Ikanda, ${ }^{24}$ A. Jacobson, ${ }^{3}$ B. Joubert, ${ }^{15}$ D. Joubert, ${ }^{15}$ M. S. Kelly, ${ }^{25}$ L. Lichtenfeld, $^{26}$ G. M. Mace, ${ }^{27}$ J. Milanzi, ${ }^{5}$ N. Mitchell, ${ }^{4,28}$ M. Msuha, ${ }^{24}$ R. Muir, ${ }^{29}$ J. Nyahongo, ${ }^{30}$ S. Pimm, ${ }^{16,17}$ G. Purchase, ${ }^{4,28} \mathrm{C}$. Schenck, $^{31}$ C. Sillero-Zubiri, ${ }^{32}$ A. R. E. Sinclair, ${ }^{33}$ A. N. Songorwa, ${ }^{34}$ M. Stanley-Price, ${ }^{6,35}$ C. A. Tehou, ${ }^{36}$ C. Trout, ${ }^{26}$ J. Wall, ${ }^{37}$ G. Wittemyer ${ }^{38}$ and A. Zimmermann ${ }^{6,21}$

\footnotetext{
${ }^{1}$ Department of Ecology, Conservation Biology and Ecology Program, Montana State University, 310 Lewis Hall, Bozeman, MT, 59717, USA

${ }^{2}$ Zambian Carnivore Programme, Box 80, Mfuwe, Eastern Province, Zambia ${ }^{3}$ Institute of Zoology, Zoological Society of London, Regents Park, London, NW1 4RY, UK

${ }^{4}$ Wildlife Conservation Society, Bronx Zoo, 2300 Southern Blvd., Bronx, NY, 10460, USA

${ }^{5}$ Zambia Wildlife Authority, Private Bag 1, Chilanga, Zambia

${ }^{6}$ Wildlife Conservation Research Unit, Department of Zoology, The RecanatiKaplan Centre, University of Oxford, Tubney House, Tubney, OX13 5QL, UK ${ }^{7}$ School of Natural Resources and the Environment, University of Arizona, Tucson, AZ, 85721, USA

${ }^{8}$ Royal Belgian Institute of Natural Sciences, 29 Vautier str., Bruxelles, 1000, Belgium

${ }^{9}$ CMS Scientific Council, UNEPICMS, Hermann-Ehlers-Str. 10, Bonn, 53113, Germany

${ }^{10}$ Max Planck Institute for Ornithology, Whitney R. Harris World Ecology Center, Washington University in St. Louis, St. Louis, 63130, USA

${ }^{11}$ Institute of Biodiversity, Animal Health and Comparative Medicine, University of Glasgow, University Avenue, Glasgow, G12 8QQ, UK

${ }^{12}$ IUCNISSC Cat Specialist Group, clo KORA, Thunstrasse 31, Muri, 3074, Switzerland

${ }^{13}$ Institute of Evolutionary Biology and Environmental Studies, Zurich University, Winterthurerstrasse 190, Zürich, CH 8057, Switzerland

${ }^{14}$ Wildlife Conservation Society, Tanzania Program, PO Box 922, Zanzibar,

Tanzania

${ }^{15}$ Big Cats Initiative, National Geographic Society, 1145 17th Street NW, Washington, DC, 20036-4688, USA

${ }^{16}$ Nicholas School of the Environment, Duke University, Durham, North Carolina, USA

${ }^{17}$ Department of Biology, Pfeiffer University, Misenheimer, North Carolina, 28109, USA

${ }^{18}$ Lion Guardians, PO Box 15550, Langata, 00509, Kenya

${ }^{19}$ Save the Elephants, PO Box 54667, Nairobi, Kenya

${ }^{20}$ Department of Zoology, University of Oxford, Oxford, OX1 3PS, UK

${ }^{21}$ Chester Zoo, Chester, CH2 1LH, UK

${ }^{22}$ Panthera, 8 West 40th Street, 18th Floor, New York, NY, 10018, USA
}

\author{
${ }^{23}$ School of Aquatic and Fishery Sciences, University of Washington, Seattle, \\ WA, 98195, USA \\ ${ }^{24}$ Tanzania Wildlife Research Institute, Box 661, Arusha, Tanzania \\ ${ }^{25}$ Department of Fish and Wildlife Conservation, Virginia Tech, 146 Cheatham \\ Hall, Blacksburg, VA, 24061-0321, USA \\ ${ }^{26}$ African People \& Wildlife Fund, PO Box 624, Bernardsville, NJ, 07924, USA \\ ${ }^{27}$ Department of Genetics, Evolution and Environment, Centre for Biodiversity \\ and Environment Research, University College London, Gower Street, London, \\ WC1E 6BT, UK \\ ${ }^{28}$ Conservation Programmes, Zoological Society of London, Regents Park, Lon- \\ don, NW1 4RY, UK \\ ${ }^{29}$ Africa Programme, Frankfurt Zoological Society Africa Regional Office, Ser- \\ engeti National Park, Serengeti, Tanzania \\ ${ }^{30}$ University of Dodoma, Dodoma, Tanzania \\ ${ }^{31}$ Frankfurt Zoological Society, Bernhard-Grzimek-Allee 1, Frankfurt, 60316, \\ Germany \\ ${ }^{32}$ Department of Zoology, IUCN/SSC Canid Specialist Group Wildlife Conserva- \\ tion Research Unit, The Recanati-Kaplan Centre, University of Oxford, Tubney \\ House, Tubney, OX13 5QL, UK \\ ${ }^{33}$ Beaty Biodiversity Research Centre, University of British Columbia, 6270 \\ University Boulevard, Vancouver, V6T 1Z4, Canada \\ ${ }^{34}$ Wildlife Division, Ivory Room, Dar es Salaam, Tanzania \\ ${ }^{35}$ IUCNISSC Species Conservation Planning Sub-committee, Rue Mauverney 28, \\ 1196 Gland, Switzerland \\ ${ }^{36}$ Coordonnateur WAPIUNOPS Bénin, B.P. 527, Cotonou, République Bénin \\ ${ }^{37}$ Laboratory for Advanced Spatial Analysis, Department of Geography, \\ University of British Columbia, 1984 West Mall, Vancouver, BC, V6T 1Z2, \\ Canada \\ ${ }^{38}$ Fish, Wildlife and Conservation Biology, Colorado State University, Fort \\ Collins, Colorado, 80523, USA \\ *Correspondence: E-mail: scree/@montana.edu
}




\begin{abstract}
Packer et al. reported that fenced lion populations attain densities closer to carrying capacity than unfenced populations. However, fenced populations are often maintained above carrying capacity, and most are small. Many more lions are conserved per dollar invested in unfenced ecosystems, which avoid the ecological and economic costs of fencing.
\end{abstract}

The highest priority of large carnivore conservation is to maintain large populations in the face of habitat loss, environmental degradation, overharvest and direct persecution (Brashares et al. 2001; Wittemyer et al. 2008; Riggio et al. 2012). Packer et al. (2013) recently argued that building fences around protected areas is the best method to conserve African lions. Their deterministic population projections suggested that all fenced populations would maintain densities near carrying capacity for 100 years, 'whereas less than half of unfenced reserves are likely to persist above $10 \%$ of their carrying capacity for the next 20-40 years' (although this statement contradicts their Fig. 3, which shows $>50 \%$ of unfenced populations remaining above the criterion for 75 years).

Packer et al.'s argument for perimeter fencing depends heavily on the criterion used to evaluate conservation success. Although they stated 'we explicitly test the effectiveness of fencing and management budgets on lion population size and growth rates,' they actually examined population density rather than population size - a critical distinction because many fenced, high-density lion populations hold few individuals. Clearly, a low-density population of 2000 individuals has more conservation value than a high-density population of 20. Consideration of this issue of scale alone weakens the argument for fencing, but other concerns exist.

\section{MANY FENCED POPULATIONS WERE MAINTAINED ABOVE CARRYING CAPACITY}

Packer et al. emphasized that lions were closer to estimated carrying capacity in fenced populations than in unfenced populations. However, mean lion density was $153.9 \%$ of estimated carrying capacity for fenced reserves smaller than $1000 \mathrm{~km}^{2}$, and $67 \%$ of these populations were maintained above carrying capacity (Fig. 1). At the extreme, lion density was $>290 \%$ of estimated carrying capacity in Madikwe and Tembwe GRs. In large areas such as the $93000 \mathrm{~km}^{2}$ Selous ecosystem, super-saturation with lions would not be possible or desirable (Creel \& Creel 1996; Durant 2000). Enclosed, supersaturated populations have conservation value, but are not a good model for conservation in naturally-regulated ecosystems. Restricting the analysis to populations at or below their carrying capacity and controlling for management expenditure per $\mathrm{km}^{2}$ (see below), lion density relative to carrying capacity was not detectably related to fencing (effect size $=2.4 \%, t_{27}=1.04, P=0.31$, OLS regression with continuous variables logged, centered and scaled, data from Packer et al. Table S1).

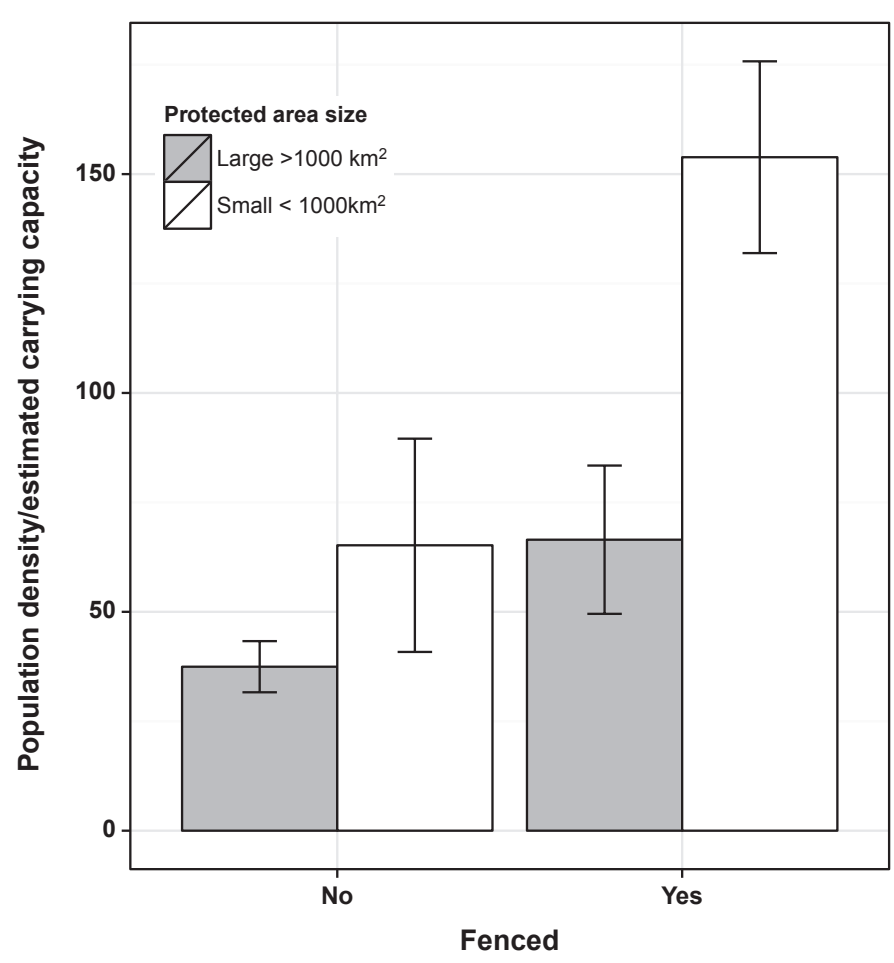

Figure 1 The relationship of lion population density to the use of perimeter fences in large and small protected areas. Density is expressed as a percentage of estimated carrying capacity, as in Packer et al. Error bars show \pm 1 SEM. In fenced reserves smaller than $1000 \mathrm{~km}^{2}$ (the majority of fenced populations) lion densities were significantly above the predicted carrying capacities reported by Packer et al. Some of the estimates of density were approximate, but we retained all estimates so that differences in our inferences and those of Packer et al. are not due to differences in the data set. However, estimation error is generally large for measures of population growth derived from such data. Packer et al. did not report variances for population density, and thus they could not propagate this variance into estimates of population growth or simulations to estimate population persistence. Incorporating such variance reduces the likelihood of persistence (Case 2001), with a stronger effect on smaller populations (most of which were fenced, see Fig. 2b).

\section{MANY FENCED POPULATIONS WERE SMALL}

In their Fig. 3, Packer et al. compared the proportions of fenced and unfenced populations that remained above $10 \%$ of estimated 
carrying capacity in deterministic projections over 100 years. To evaluate this result, one must recognize that for 10 of 17 fenced reserves, $10 \%$ of carrying capacity is $\leq 5$ lions. Because Packer et al.'s criterion does not directly consider population size, as few as 29 lions across 10 fenced reserves would be considered 10 successes, while the conservation of 640 lions in the Selous Game Reserve would be considered a failure. A population of 640 lions that is below its carrying capacity has more conservation value and potential than a smaller number of lions already at higher density. Clearly, population sizes must be explicitly considered for meaningful conservation priorities.

\section{FENCED AND UNFENCED RESERVES DIFFER IN WAYS OTHER THAN FENCING}

Fenced protected areas were operated with median expenditure per $\mathrm{km}^{2} 7.6$ times larger than unfenced areas (Fig. 2a, $t_{38}=3.72$, $P=0.00064$, medians: $1900 \mathrm{USD} \mathrm{km}^{-2}, 251 \mathrm{USD} \mathrm{km}^{-2}$ ). Fenced reserves were $1 / 11$ th the size of unfenced reserves (Fig. 2b, medians: $399 \mathrm{~km}^{2}, 4471 \mathrm{~km}^{2}$ ). This difference in area is important because it affects total population size, and because the effect of fencing on density was much stronger in small reserves (Fig. 1). Finally, lions in most fenced areas were managed more intensively [e.g. translocations into $56 \%$ of fenced populations during the period of study (often repeatedly) vs. $0 \%$ of unfenced reserves; anthropogenic removals were common in both types].

\section{CONSERVATION OF UNFENCED LION POPULATIONS WAS MORE COST EFFECTIVE}

Packer et al. presented data on lions $/ \mathrm{km}^{2}$ and management expenditure $/ \mathrm{km}^{2}$, from which we calculated lions conserved per dollar of management expenditure. For each management dollar, unfenced reserves conserved many more lions than fenced reserves. (Fig. 2c, $\left.t_{37}=2.11, P=0.042\right)$.
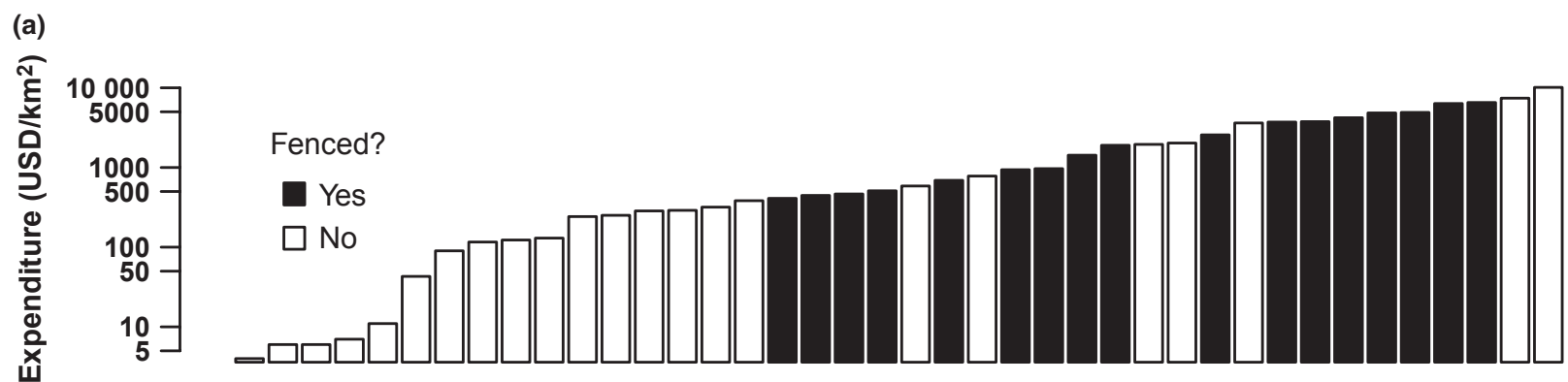

(b)

$$
\text { สี }
$$

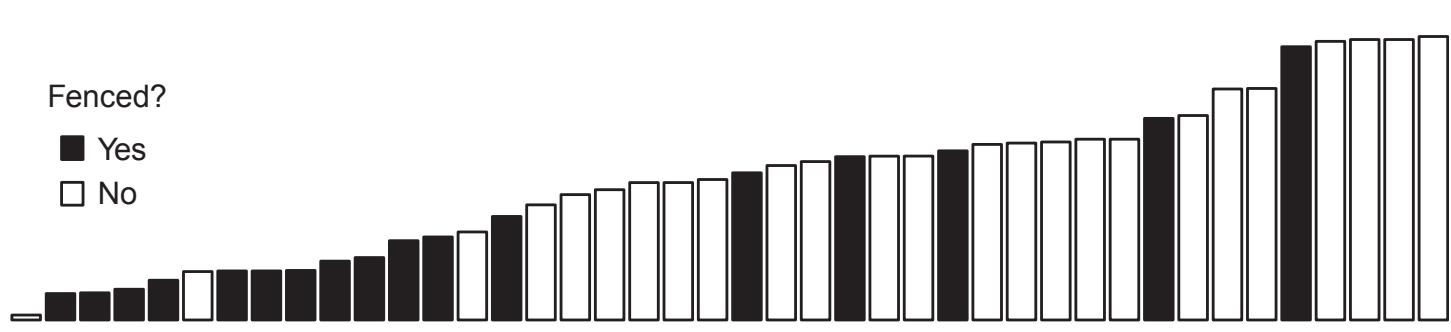

(c)

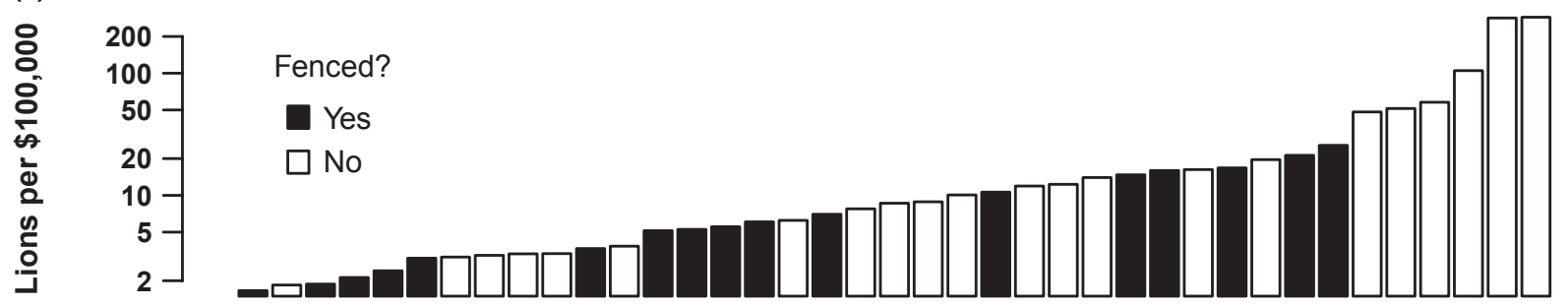

Figure 2 Lion populations with and without perimeter fences, ranked by (a) management expenditure per $\mathrm{km}^{2}$, (b) protected area size and (c) lions conserved per $\$ 100000$ of management expenditure. Unfenced populations were larger, were managed with smaller budgets (per unit area), and were more cost-effective. The ordinate is logarithmically scaled in all panels. In panel C, we assume that lion density (like other ecological attributes) responds directly or indirectly to the level of management expenditure used to conserve an area. If lion density was estimated for a subset of a protected area, we assume similar effects of expenditure on lion density (but not equal density) inside and outside the study site. The significantly larger number of lions conserved per dollar of management expenditure in unfenced populations runs opposite to the primary inference of Packer et al., although they did not present any statistical test of cost-effectiveness. 


\section{FENCES CAUSE A BROAD RANGE OF ECOLOGICAL, ECONOMIC AND SOCIAL EFFECTS}

Fences can prevent edge effects from penetrating into protected areas and reduce conflicts outside protected areas (Ogada et al. 2003; Hayward \& Kerley 2009), but also carry important costs, including ecosystem fragmentation, loss of dispersal and migration routes, genetic isolation, reduced conservation value of buffer zones (and consequent loss of wildlife-based economic benefits in buffer zones), and utilization of fencing materials for wire snare poaching (Newmark 1996, 2008; Hayward \& Kerley 2009; Lindsey et al. 2011; Gadd 2012; Becker et al. 2013). Lions can maintain good densities with little conflict in areas that maintain connectivity for wildlife while allowing avoidance of people and livestock (Schuette et al. 2013). We concur with Packer et al. that effective lion conservation will require better funding, but rather than fencing, we recommend better-funded law enforcement inside reserves, reduced and better-regulated hunting, landscapelevel strategies that reduce human-wildlife conflict outside reserves, and a high priority for conservation in large and intact ecosystems.

\section{ACKNOWLEDGEMENTS}

The information on lion population densities compiled by Packer et al. 2013 represents a huge volume of work by many individuals; while we do not agree with the paper's conclusions, we respectfully acknowledge all of the individuals who contributed data and have worked for carnivore conservation in many ways. This research was supported by the National Science Foundation Animal Behavior Program under IOS-1145749, WWF-Netherlands, the Big Cats Initiative of the National Geographic Society, and Painted Dog Conservation Inc.-Australia. Wigganson Matandiko was supported by a Fulbright fellowship from the Institute for International Education, and Jassiel M'Soka was supported by a Schink Scholarship from the Wildlife Conservation Network.

\section{AUTHORSHIP}

All authors contributed to the development of hypotheses and points of discussion. Scott Creel conducted the statistical and graphical analysis. Scott Creel, Sarah Durant and Matt Becker wrote the first draft.

\section{REFERENCES}

Becker, M.S., McRobb, R., Watson, F., Dröge, E., Kanyembo, B. \& Kakumbi, C. (2013). Evaluating wire-snare poaching trends and the impacts of by-catch on elephants and large carnivores. Biol. Conserv., 158, 26-36.

Brashares, J., Arces, P. \& Sam, M.K. (2001). Human demography and reserve size predict wildlife extinction in West Africa. Proc. Roy. Soc. Lond. Ser. B, 268, 2473-2478.

Case, T.J. (2001). An Illustrated Guied to Theoretical Ecology. Oxford University Press, New York.

Creel, S. \& Creel, N.M. (1996). Limitation of African wild dogs by competition with larger carnivores. Cons. Biol., 10, 526-538.

Durant, S. (2000). Living with the enemy: avoidance of hyenas and lions by cheetahs in the Serengeti. Behav. Ecol., 11, 624-632.

Gadd, M. (2012). Barriers, the beef industry and unnatural selection: a review of the impact of veterinary fencing on mammals in Southern Africa. In: Fencing for Conservation: Restriction of Evolutionary Potential or a Riposte to Threatening Processes? (eds Sommers, M.J. \& Hayward, M.). Spring Science, New York, 153-186.

Hayward, M.W. \& Kerley, G.I.H. (2009). Fencing for conservation: restriction of ecological potential or a riposte to threatening processes? Biol. Cons., 142, 113.

Lindsey, P.A., Romañach, S.S., Tambling, C.J., Chartier, K. \& Groom, R. (2011). Ecological and financial impacts of illegal bushmeat trade in Zimbabwe. Oryx, 45, 96.

Newmark, W.D. (1996). Insularization of Tanzanian parks and the local extinction of large mammals. Conserv. Biol., 10, 1549-1556.

Newmark, W.D. (2008). Isolation of African protected areas. Front. Ecol. Environ., 6, 321-328.

Ogada, M.O., Woodroffe, R., Oguge, N. \& Frank, L.G. (2003). Limiting depredation by African carnivores: the role of livestock husbandry. Cons. Biol., 17, 1521-153.

Packer, C., Loveridge, A., Canney, S., Caro, T., Garnett, S.T., Pfeifer, M. et al. (2013). Large carnivore conservation: dollars and fence. Ecol. Lett., 16, 635641.

Riggio, J., Jacobson, A., Dollar, L., Bauer, H., Becker, M., Dickman, A. et al. (2012). The size of savannah Africa: a lion's (Panthera leo) view. Biodiv. \& Cons., 22, 17-35.

Schuette, P., Creel, S. \& Christianson, D. (2013). Coexistence of African lions, livestock, and people in a landscape with variable human land use and seasonal movements. Biol. Cons., 157, 148-154.

Wittemyer, G., Elsen, P., Bean, W.T., Coleman, A., Burton, O. \& Brashares, J.S. (2008). Accelerated human population growth at protected area edges. Science, 321, 123-126. 